\title{
Our health system and the poorest Americans
}

\author{
George A. Beller, MD
}

It is well recognized that the gap between the wealthiest and the poorest Americans has been widening for many years. The main safety net for health care among those in poverty has been the Medicaid program. The new health care law can provide federal subsidies to those who have incomes from the poverty level to four times that amount $(\$ 11,490$ to $\$ 45,960) .{ }^{1}$ The new law also expanded the Medicaid program with mostly federal funding, but about half of the states have so far refused to expand Medicaid. This is going to leave millions of poor Americans deprived of medical insurance coverage. In the states refusing to participate in the expanded Medicaid program, those individuals having incomes below the poverty level will be unable to get tax credits toward low cost insurance, Medicaid, or other assistance for health insurance. For example, the New York Times article on this subject ${ }^{1}$ pointed out that the Kansas Medicaid Program will provide no assistance for coverage for adults with incomes from $32 \%$ to $100 \%$ of the poverty level ( $\$ 6,250$ to $\$ 19,530$ for a family of three) as they are one of the states which chose not to expand their Medicaid program. A scenario cited was that for the main breadwinner of a family of four living in Louisiana, who works full time in a job paying $\$ 14$ an hour, he or she will be eligible for insurance subsidies. Ironically, if such a person makes $\$ 10$ an hour, he or she would not be eligible for any time of assistance to gain health care coverage. As of this writing, some other states refusing to expand Medicaid, and thus excluding the poorest Americans for assistance in health care coverage, include Texas, Florida, and Georgia.

The Times article mentions that the Congressional Budget Office estimated that under the new health care law, approximately 25 million people will gain insurance coverage. ${ }^{1}$ For those states refusing to expand Medicaid eligibility, about 5.7 million uninsured adults below the poverty level will not gain coverage. What does this say about our already dysfunctional health care system where the cost of health care is the highest in the world yet our life expectancy ranks lower than many of our peer countries? How can we have arrived at a situation where the poorest of the poor will not get government assistance for health care in half of the states in the country? Deborah $\mathrm{H}$.

J Nucl Cardiol 2013;20:500.

$1071-3581 / \$ 34.00$

Copyright $\odot 2013$ American Society of Nuclear Cardiology.

doi:10.1007/s12350-013-9740-0
Tucker, the chief Executive of a community health center in Tuscaloosa, Ala., is quoted in the Times article saying that, "it was wonderful that many uninsured people would gain coverage, but tragic that some of the most vulnerable, lowest-income people would be excluded.' She further states that her clinics in Tuscaloosa see nearly 30,000 patients a year, including 16,000 who are uninsured. Of the uninsured, $75 \%$ have incomes below the poverty level and are unlikely to qualify for Medicaid or subsidies.

If the states that refused to participate in the expansion of Medicaid continue to do so in the ensuing months and years, not only will the health of those without coverage suffer but those hospitals and outpatient facilities that care for these individuals will undergo great financial stress. One would have to think twice about ordering an expensive diagnostic procedure for someone under the poverty level with absolutely no health care insurance coverage. It is well recognized that self-pay patients without health insurance coverage are billed at the highest level for procedures. Such a situation could bankrupt many such poor individuals if they were pressed to pay the full amount of their medical bills by collection agencies acting on behalf of hospitals. And, hospitals which care for the poor would also become financially troubled, and might have to cut services to the neediest Americans. We know that cardiovascular care for primary and secondary prevention of coronary artery disease, and evidence-based therapy for patients with heart failure, save lives and markedly reduce morbidity. Such care should be available to all segments of our society, and in all our states, regardless of ability to pay. Many of those poor people in states not expanding Medicaid do have jobs, but make below the amount that makes them eligible for assistance in the form of insurance subsidies under the new health care law. This unwillingness of some states to expand Medicaid, that is predominantly being supported by increased federal funding, will further contribute to the widening socioeconomic disparities in health care in the United States. One consequence will be worse cardiovascular outcomes with higher cardiac mortality and morbidity for many uninsured poor people in this country.

\section{Reference}

1. Pear R. States' policies on health care exclude the poorest: Wide gap on medicaid. New York Times, May 25, 2013. 